\title{
STRAW BASED PARTICLEBOARD BONDED WITH COMPOSITE ADHESIVES
}

\author{
Yanhua Zhang, Jiyou Gu, ${ }^{*}$ Haiyan Tan, Mingwei Di, Libin Zhu, and Xiangli Weng \\ Environmentally friendly particleboard was prepared with wheat straw, an \\ inexpensive material. The particleboard was produced by a mixing \\ process, using a composite adhesive comprised of urea-formaldehyde \\ (UF) adhesives and EPU. The performance of the board was evaluated \\ by measuring internal bonding strength (IB), thickness swelling, modulus \\ of rupture (MOR), modulus of elasticity (MOE), and formaldehyde \\ emission. The experimental results showed that maximum of dry and \\ wet internal bonding strength, modulus of rupture, modulus of elasticity \\ were $0.45 \mathrm{MPa}, 0.18 \mathrm{MPa}, 31.80 \mathrm{MPa}$, and $5043 \mathrm{MPa}$, respectively. The \\ thickness swelling (TS2h) and thickness swelling (TS24h) were 3.9\% \\ and $10.7 \%$, respectively. The composite adhesives and particleboards \\ were measured by differential scanning calorimentry (DSC), dynamic \\ mechanical analyzer (DMA), X-ray photoelectron spectroscopy (XPS) \\ and scanning electron microscope (SEM) measurements. The results \\ indicated that the composite adhesive of UF/EPU could contribute to \\ excellent mechanical, thermal, and water-resistant properties of the \\ wheat straw particleboards.
}

Keywords: Particleboards; Wheat straw; Composite adhesive; DSC; XPS; SEM

College of Material Science and Engineering of Northeast Forestry University, Harbin, China, 150040;

*Corresponding author: dldgujy@163.com

\section{INTRODUCTION}

The demand for glued-wood composite products such as particleboard, medium density fiberboard, and plywood has increased dramatically throughout the world in recent years (Sellers 2001; Youngquist 1999; Zheng et al. 2007). At present, increasing demand of particleboards from forest resources in housing construction and furniture manufacturing sectors have led to a shortage of wood supply (Zheng et al. 2007; Singha. 2008). On the other hand, large quantities of agricultural residues, including harvesting residues, barks, lumber and furniture plant residues, residues of pulp plants, and recycled paper are available for woodware production in place of wood. Wheat straw (WS) is a renewable agricultural by-product. In China, more than $1.2 \times 1012$ tons of WS is produced annually, with a large quantity of the WS being incinerated or discarded in the environment. Although the chemical composition of WS is similar to that of wood, comprising cellulose structures in an amorphous matrix of hemicelluloses and lignin, its structure is looser and its strength is lower; it also contains less lignocellulosic materials and more ash and extractives with lower molecular weights than wood. Furthermore, silica and waxy substances on the exterior surfaces of WS tend to interfere with its bonding to other materials when using conventional adhesives such as urea formaldehyde (UF) or phenol formaldehyde (PF) (Yao et al. 2003; Mo et al. 2003; Liu et al. 2002; 
Wang et al. 2009). The advantages of straw particleboards include built-in insulation, sound suppression characteristics, and low cost (Boquillon 2005). In addition, several types of adhesive resins have been used to make straw particleboard. Among these adhesives, urea-formaldehyde is the most economical and useful adhesive because of its low cost and easy production (Guru et al. 2005). But there are also some disadvantages, such as poor water resistance, especially intolerance boiling water, and less durability. These problems are compounded by formaldehyde emission, resulting in harm to the environment and the human body. On the other hand, isocyanates are highly reactive to amines and urethane, which are sensitive to nucleophilic reagents under both acidic and basic mediated condition (Blencowe et al. 2006). The advantages of isocyanate adhesives include shorter time and lower temperature for hot pressing, and less dry materials cost, which could improve productivity of wheat straw-based composites (Gallbraith 1986). The cost of isocyanate, which may be used as an adhesive for wood and wheat straw, is substantially greater than other wood adhesives such as urea formaldehyde, phenol-formaldehyde, and melamine-formaldehyde, based on weight (Han et al. 1998). Making advantageous use of isocyanate and urea-formaldehyde resins to achieve low-cost production of high-performance, environmentally friendly particleboard is an innovative point of this study (Kang 2001; Mo et al. 2001). And the mechanical properties of wheat straw particleboards bonded by composite adhesive with UF and EPU (emulsifiable pMDI) can be improved greatly without removing wax and ash from the wheat straw surface through bleaching with oxidizing agents and alkali.

The aim of this study was to investigate the effect of mechanical properties and water resistance of particleboard made from wheat straw, depending on the ratio of composite adhesive. All chaff, nodes, leaves, and broken kernels do not need to be removed for preparing particleboards with composite adhesive. Furthermore, the composite adhesives and the boards were investigated by using differential scanning calorimetry (DSC) and dynamic mechanical analyzer (DMA), respectively. The study of morphology and chemical state requires a reliable method to analyze wheat straw particleboards. X-ray photoelectron spectroscopy (XPS) and SEM provide a chemical analysis and morphology of the glue line substrate in the boards. As described in this paper, a variety of characterization procedures for wheat straw particleboard can provide a strong theoretical basis for production practices.

\section{EXPERIMENTAL}

\section{Materials}

Wheat straw raw material was obtained from a local farm. The stems were first cut into 100 to $150 \mathrm{~mm}$ lengths by a drum chipper and further refined into $10 \mathrm{~mm}$ using ring flakers. All of the $10 \mathrm{~mm}$ straw was further oven-dried at $80{ }^{\circ} \mathrm{C}$ to about $4 \%$ moisture content and stored in plastic bags, which were kept in the wood based panel laboratory.

Urea-formaldehyde (UF) is the dominant adhesives for making the particleboard. The UF resin was synthesized by our laboratory; one of the mole ratios was 1.3 of the $\mathrm{E}_{2}$ 
type. The resin solid content and urea/formaldehyde molar ratio of the UF resin were 60$62 \%$ and 1.3 , respectively.

Polymeric methane dipthenyl diisocyanate (pMDI) was supplied by Bayer Polymer Ltd. Co. (branch company, China); it contains $32.9 \%$ of NCO with an average functionality of 2.7. Ammonium chloride, used as a hardener, was purchased from TianJin BoDa Chemical Co. Other agents such as formic acid, sodium hydroxide, urea, and formaldehyde and sodium bisulphate were purchased from TianJian Huabei Co. The EPU was prepared by the reaction of the pMDI with the NP40.

\section{Straw Particleboards Manufacturing}

The UF resin was synthesized with mole ratio (U/F) of 1.3. The solids content in the adhesive solutions was $62 \%$. The composite adhesive involved adding EPU with different ratios into the UF resin, achieving highly stable mixtures. The composite adhesive was sprayed in the form of particles in a blender at $10 \%$ resin content based on the oven-dried weight of particles. Particleboards of $400 \times 400 \times 12 \mathrm{~mm}$ were manufactured at a target density of $750 \pm 10 \mathrm{~kg} / \mathrm{m}^{3}$ with an adhesive content of $10 \%, 6 \mathrm{~min}$ of hot-press time, and $170{ }^{\circ} \mathrm{C}$ of hot-press temperature.

\section{Preparation of composite adhesive}

Emulsifiable polyisocyanate adhesive preparation

Depending on the desired molar ratio of $-\mathrm{NCO}$ and $-\mathrm{OH}$, a certain quality of $\mathrm{p}$ MDI and polyether polyols were placed into a three-necked bottle and churned up at a rotational speed of 500r/s. Meanwhile nitrogen gas was injected into the reactor for 30 minutes, preparing the system to react for 5 hours in an oil bath at the temperature of $70 \pm 2^{\circ} \mathrm{C}$. When the reaction was finished, the reaction system was allowed to cool to room temperature $\left(40 \pm 3{ }^{\circ} \mathrm{C}\right)$ and the products of reaction were taken out.

Preparation of the composite adhesive

After preparing the emulsifiable polyisocyanate and urea formaldehyde mixture according to a certain ratio, a small quantity of accessory ingredient was added and the mixture was blended rapidly for 10 to 15 minutes until a light yellow emulsion adhesive was obtained.

\section{Straw Particleboards Evaluation}

Mechanical properties, including modulus of rupture (MOR), modulus of elasticity (MOE), internal bond strength (IB), and water resistance are very important specifications for particleboards. They were measures of finished particleboard. The straw particleboards were cut into test specimens according to national standard of GB/T 9846. The dimensions of the sample were $5.0 \times 5.0 \mathrm{~cm}$ square shape for internal bond measurement and for boiling water internal bond measurements. The dimensions were $5.0 \times 17.0 \mathrm{~cm}$ for three-point flex measurement of MOR and MOE, respectively. All specimens were equilibrated at a temperature of $20{ }^{\circ} \mathrm{C}$ and $65 \%$ relative humidity $(\mathrm{RH})$ before testing. Mechanical properties were determined by using a testing machine and following ASTM standard method GB/T 9846.1, 9846.8 (2004). Water absorption and thickness swell were measured according to the ASTM standard methods. The $50 \times 50$ 
$\mathrm{mm}$ pieces of the particleboard were soaked in water at room temperature for $2 \mathrm{~h}$. The thickness and weight were measured immediately after soaking. The dimensional size and weight measured before and after soaking were obtained. Then the average results were calculated from four specimens.

\section{Differential Scanning Calorimetry Measurements (DSC)}

To examine the curing behavior of each UF/EPU resin, differential scanning calorimertry (DSC) (Netzsch 204 Instruments, Germany) and a high-pressure pan were used. Each composite adhesive used for DSC measurement were the same samples as those used to assess gel time, and they were scanned at a heating rate of $5{ }^{\circ} \mathrm{C} / \mathrm{min}$, with a temperature range of 30 to $200{ }^{\circ} \mathrm{C}$.

\section{Dynamic Mechanical Analysis Measurements (DMA)}

The samples of the straw particleboard can be studied by the DMA technique (No and Kim 2005). A three-point bending mold was employed for the test. The dimensions of samples were $40 \times 8 \times 2.5 \mathrm{~mm}$. A fixed displacement mode with $60 \mathrm{~mm}$ amplitude and $10 \mathrm{~Hz}$ oscillation frequency was used. The temperature program started with an equilibration waiting period at room temperature, followed by increasing temperature at the same rate of $5{ }^{\circ} \mathrm{C} / \mathrm{min}$ to $290{ }^{\circ} \mathrm{C}$. DMA instrumental analysis was used to obtain the rigidity (storage modulus, $\left.\mathrm{G}^{\prime}\right)$ and tan delta $\left(\delta, \mathrm{G}^{\prime \prime} / \mathrm{G}^{\prime}\right)$ curves.

\section{X-ray Photoelectron Spectroscopy (XPS) and Scanning Electron Microscope (SEM) Measurements}

XPS measurements were performed at room temperature with monochromatic $\mathrm{AlK} \alpha$ radiation $(1486.6 \mathrm{eV})$ using a K-Alpha X-ray photoelectron spectrometer (supplied by Thermo Fisher Scientific Co., Ltd). The X-ray beam was a 100-W, 200mm-diameter beam raster over a $2 \mathrm{~mm}$ by $0.4 \mathrm{~mm}$ area on the sample. High-energy photoemission spectra were collected using pass energy of $50 \mathrm{eV}$ and resolution of $0.1 \mathrm{eV}$. For the $\mathrm{Ag} 3 \mathrm{~d} 5 / 2$ line, these conditions produced an FWHM of $0.80 \mathrm{eV}$. A Quanta 200 scanning electron microscopy (supplied by FEI Co., Ltd) was used for the investigation of the morphology of the wheat straw particleboards.

\section{RESULTS AND DISCUSSION}

\section{DSC Characteristics of Composite Adhesive with UF Resin Modified by EPU}

Differential Scanning Calorimetry (DSC) analysis has been broadly applied for UF resin curing research. Because of the fact that the urea-formaldehyde resin was added at different ratios of EPU, its curing conditions would not necessarily be constant. For evaluation of the composite effect of urea-formaldehyde resin and the EPU in bonding, DSC can accurately determine whether the modified resin can fully fill the role of an adhesive for this type of product.

With other conditions fixed, to change the add EPU ratio, the composite adhesive were characterized by DSC, as shown in Fig. 1 and Table.1 
Table 1. Cure Temperature of UF Resin Modified by EPU

\begin{tabular}{|ccccc|}
\hline Label & Onset $/{ }^{\circ} \mathrm{C}$ & $\mathrm{Peak} /{ }^{\circ} \mathrm{C}$ & $\mathrm{End} /{ }^{\circ} \mathrm{C}$ & Area $/ \mathrm{J} / \mathrm{g}$ \\
\hline UF0 & 78.6 & 82.9 & 98.5 & -29.2825 \\
\hline UF1 & 61.3 & 77.2 & 86.8 & -61.435 \\
\hline UF2 & 57.8 & 76.5 & 85.2 & -127.717 \\
\hline UF3 & 51.7 & 76.7 & 85.0 & -58.098 \\
\hline
\end{tabular}

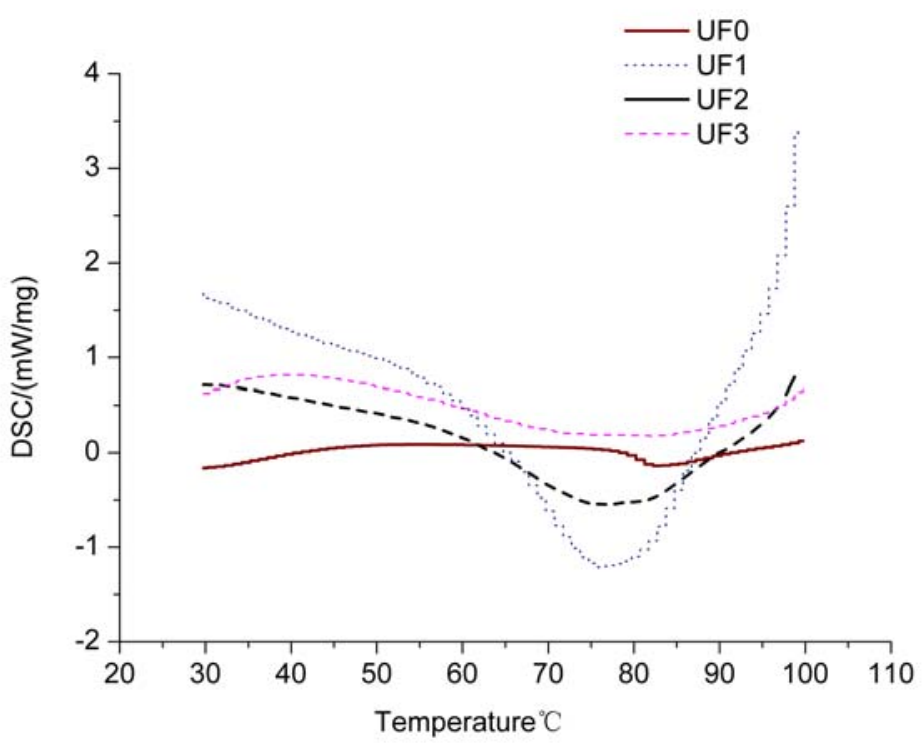

Fig. 1. DSC curves of UF resin modified by EPU

From the chart it is clear that the cured properties of composite adhesives exhibited significant differences. As the addition of EPU gradually increased, the lower initial temperature of the DSC curve, as well as the curing, began at a lower temperature. From the point of view of the peak temperature and the end of the temperature curve, its highest conversion rate of curing and temperature of curing began with the same trend. This implies that the urea-formaldehyde resin modified by EPU can promote ureaformaldehyde resin curing speed and facilitate complete curing. Judging from the area of the UF2 maximum heat release, heat was released due to the EPU and urea-formaldehyde resin curing or water reaction. And with the addition of EPU the amount of heat released gradually increased. When the UF/EPU ratio was 70/30, there was no exothermic peak in the DSC curve; this was attributed to the fact that isocyanate addition increased. These considerations may induce faster reaction with the water than urea-formaldehyde resin, possibly covering up the UF resin curing characteristics peak, thus giving rise to a wide exothermic peak. To sum up, the use of DSC method can provide a very good characterization of urea-formaldehyde resin curing properties, and it is clear from the spectra that EPU mixed with the urea-formaldehyde resin can promote the curing reaction. 


\section{Properties of Wheat Strawboards}

The properties of UF/EPU mixtures bonded particleboards comprising different ratios of UF/EPU are presented in Table 2. Glue-mixes composed of UF/EPU weight ratios of 70/30, 80/20, 90/10, and 100/0(UF control) were prepared. To all the glue mixes were added 5\% ammonium chloride aqueous solutions on UF resin. The results in Table 2 indicate that the performance of strawboards was significantly improved by the increasing addition of EPU. This is because both reactions of isocyanate with the water and hydroxyl groups in the straw can generate crosslinked polyureas or polyurethanes, leading to strong mechanical bonding. Straw particleboards bonded using UF resin exhibited poorer mechanical properties than those with added EPU. With increasing addition of isocyanate, straw boards of MOE, MOR, and IB did not follow the same trend, but the results met or exceeded national standards, and free formaldehyde also stayed below E0-type limits. Because of the increasing addition of isocyanate will increase the cost, a ratio of 80/20 composite adhesive was selected.

As shown in Table 3, the ratio of urea-formaldehyde resin to EPU was fixed at $80 / 20$, to change the adhesive amount of composite $(9 \%, 10 \%, 11 \%, 12 \%)$ based on dried straw. With the increase amount of composite adhesive, straw board MOE, MOR, and IB gradually improved, and straw board dimensional stability, which depended on the precise nature of the increased use of composite adhesive. However, straw board of formaldehyde emission was also increased with the amount of composite adhesive increase. From the results from Tables 2 it is evident that by the use of common ureaformaldehyde resin $(\mathrm{F} / \mathrm{U}=1.3)$ and isocyanate composite adhesive, when the UF / EPU ratio is $80 / 20$, an amount adhesive of $11 \%$ achieved excellent performance in meeting the E0 straw board specifications.

Table 2. Properties of Particleboard with Different Ratio of Composite Adhesive

\begin{tabular}{|c|c|c|c|c|c|c|c|c|}
\hline UF/ EPU & $\begin{array}{c}\text { density } \\
\left(\mathrm{g} / \mathrm{cm}^{3}\right)\end{array}$ & $\begin{array}{c}\mathrm{MOE} \\
(\mathrm{MPa})\end{array}$ & $\begin{array}{c}\mathrm{MOR} \\
(\mathrm{MPa})\end{array}$ & $\begin{array}{c}\mathrm{IB}_{\mathrm{D}} \\
(\mathrm{MPa})\end{array}$ & $\begin{array}{c}\mathrm{IB}_{\mathrm{w}} \\
(\mathrm{MPa})\end{array}$ & $\begin{array}{c}\mathrm{TS} \\
(2 \mathrm{~h})(\%)\end{array}$ & $\begin{array}{c}\mathrm{TS} \\
(24 \mathrm{~h})(\%)\end{array}$ & $\begin{array}{c}\mathrm{FF} \\
\mathrm{mg} / 100 \mathrm{~g}\end{array}$ \\
\hline $70 / 30$ & 0.70 & 4303 & 26.95 & 0.36 & 0.11 & 9.0 & 24.8 & 0.24 \\
\hline $80 / 20$ & 0.74 & 5010 & 35.04 & 0.72 & 0.16 & 4.7 & 13.7 & 0.89 \\
\hline $90 / 10$ & 0.78 & 4783 & 28.56 & 0.55 & 0.14 & 5.6 & 13.9 & 0.24 \\
\hline $100 / 0$ & 0.72 & 3164 & 13.6 & 0.12 & 0.08 & 15.0 & 35.7 & 1.12 \\
\hline
\end{tabular}

Table 3. Properties of Particleboard with Different Amount of Adhesive at the Ratio of $80 / 20$

\begin{tabular}{|c|c|c|c|c|c|c|c|c|}
\hline $\begin{array}{c}\text { Amount of } \\
\text { adhesive } \\
(\%)\end{array}$ & $\begin{array}{c}\text { density } \\
(\mathrm{g} / \mathrm{cm} 3)\end{array}$ & $\begin{array}{c}\text { MOE } \\
(\mathrm{MPa})\end{array}$ & $\begin{array}{c}\text { MOR } \\
(\mathrm{MPa})\end{array}$ & $\begin{array}{c}\text { IBD } \\
(\mathrm{MPa})\end{array}$ & $\begin{array}{c}\text { IBW } \\
(\mathrm{MPa})\end{array}$ & $\begin{array}{c}\text { THS } \\
(2 \mathrm{~h})(\%)\end{array}$ & $\begin{array}{c}\text { THS } \\
(24 \mathrm{~h})(\%)\end{array}$ & $\begin{array}{c}\mathrm{FF} \\
\mathrm{mg} / 100 \mathrm{~g}\end{array}$ \\
\hline 9 & 0.74 & 4944 & 35.33 & 0.51 & 0.10 & 6.4 & 16.6 & 0.09 \\
\hline 10 & 0.74 & 5010 & 35.04 & 0.72 & 0.16 & 4.7 & 13.7 & 0.89 \\
\hline 11 & 0.76 & 5043 & 31.80 & 0.45 & 0.18 & 3.9 & 10.7 & 0.50 \\
\hline 12 & 0.76 & 4829 & 32.00 & 0.56 & 0.05 & 3.8 & 10.0 & 1.49 \\
\hline
\end{tabular}




\section{DMA Measurement}

DMA tests were used to investigate the effect of different composite adhesive proportions on the thermomechanical properties of the prepared straw particleboards, as shown in Fig. 2. The DMA results of UF/EPU composite were conducted at 70/30, $80 / 20$, and $90 / 10$ ratios. From Fig. 2 it is clear that the preparation of straw particleboard with the ratio of $90 / 100$ had a lower storage modulus. As the addition of isocyanate increased, its storage modulus increased markedly. It is noticeable that the UF/EPU $70 / 30$ mix reached a maximum value of the modulus of $7000 \mathrm{MPa}$. The reason for the observed enhancement in curing with the isocyanate has been ascribed to the higher reactivity of isocyanate than urea, thus achieving a stronger adhesion to straw. Therefore, we can conclude that isocyanate can accelerate the curing reaction of urea-formaldehyde resin, especially enhancing the strength of straw particleboard bonding. However, the tan-delta curves of all straw particleboards decreased slightly as the composite ratio increased from $90 / 10$ to $70 / 30$, and the loss modulus for $90 / 10$ s particleboard was distinctly greater than that of the $80 / 20$ and $70 / 30$ particleboards.

The results in Figs. 2 and 3 could not confirm that a mutual reaction of UF with EPU indeed occurs to a greater or smaller extent, but leads to a thermally stable structure formed by a main product that is different than what were previously small isocyanate molecules. Overall, the optimized system with a composite ratio of 70/30 exhibited a high storage modulus. However, the ratio of $80 / 20$ complex conditions would be able to meet the requirements. But from cost considerations, we can choose the proportion of $80 / 20$ preparation of wheat straw particleboard.

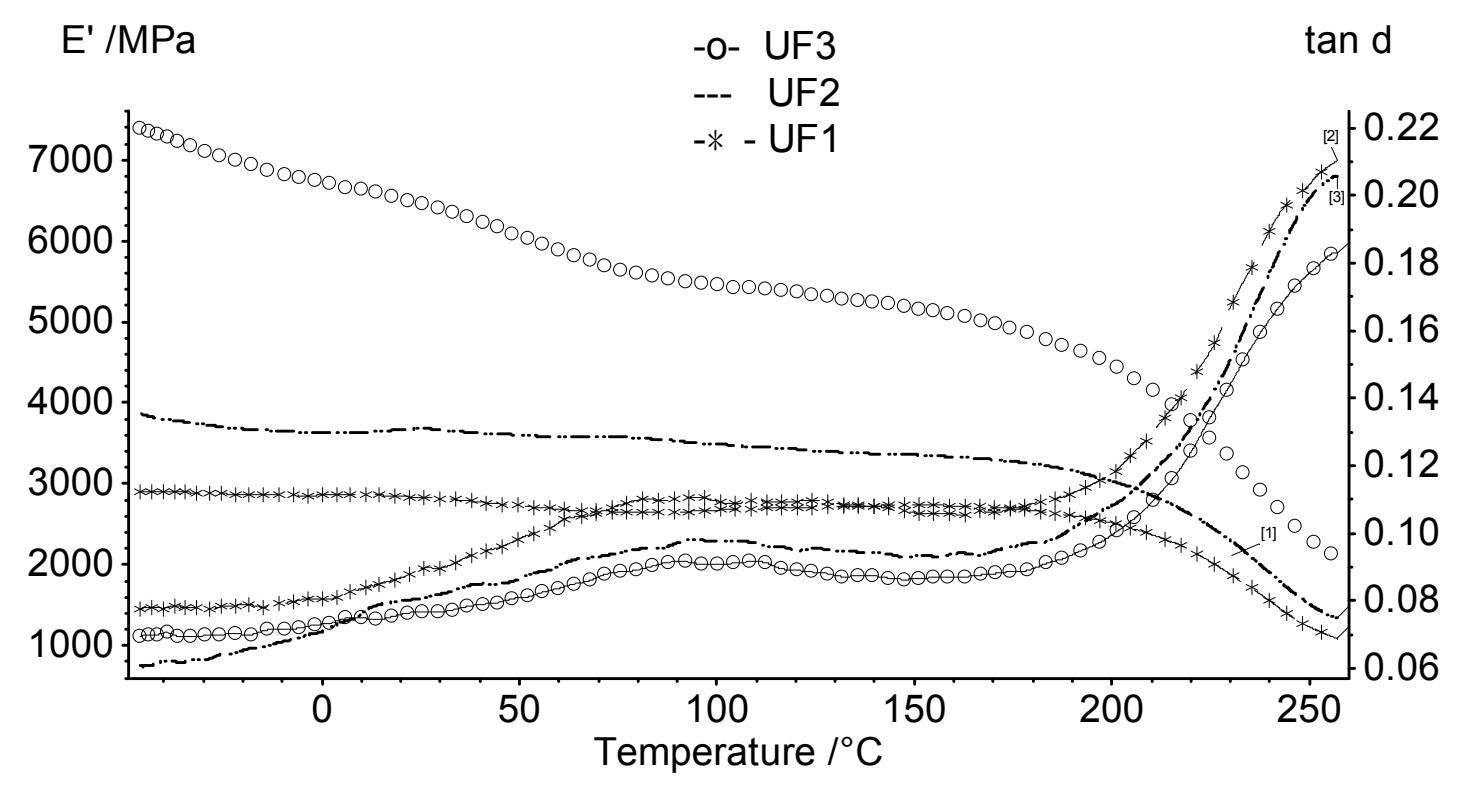

Figure 2. Storage modulus and tan delta of straw particleboards with different proportions of UF/EPU 


\section{X-ray Photoelectron Spectroscopy (XPS) Analysis}

X-ray photoelectron spectroscopy (XPS) analysis was used to characterize the chemical changes of the wheat straw particleboards. In the high resolution spectra of C1s, as shown in Fig. 4 and Table 4, it is evident that the C1s spectra of the samples consisted of four well-resolved peaks. The curve-fitting simulation was carried out after subtracting the baseline correction.

The peaks of carbon atoms at $285.0 \mathrm{eV}, 286.2-286.4 \mathrm{eV}, 287.2-287.9 \mathrm{eV}$, and $289.3-290.7 \mathrm{eV}$ corresponded to the carbon atoms that can be described in abbreviated form as $\mathrm{C}-\mathrm{C}$ or $\mathrm{C}-\mathrm{H}$, the carbon atoms a singly bonding to oxygen (ether group C-C-O), the carbon atoms double-bonded to oxygen and nitrogen in the urethane linkage (-O$\mathrm{C}=\mathrm{O})$, and the carbon atoms double-bonded to oxygen and nitrogen $(-\mathrm{N}-\mathrm{C}=\mathrm{O})$ in the imides group, respectively. The peak-fitted $\mathrm{C} 1 \mathrm{~s}$ spectra correspond to wheat straw particleboards with the composite ratios UF/EPU of 100/0, 90/10, 80/20, and 70/30, respectively. The peak fitting of the C1s spectra from the data set is illustrated in Fig 3 . The carbon chemical state demonstrated a slight decrease of the ether group with an increase of amount of EPU, suggesting a modification of the glue line of wheat straw particleboards.

Table 4. Binding Energy (eV) and Relative Intensity (\%) of the High-Resolution C1s Peak Fitting Signals for the Reference UF and EPU

\begin{tabular}{|c|c|c|c|c|}
\hline $\begin{array}{c}\text { Sample } \\
\text { UF/EPU }\end{array}$ & $\begin{array}{c}\mathrm{C} 1(285.0 \mathrm{eV}) \\
(\underline{\mathrm{C}}=\mathrm{C} / \underline{\mathrm{C}}-\mathrm{H})\end{array}$ & $\begin{array}{c}\mathrm{C} 2(286.3-286.4 \mathrm{eV}) \\
\mathrm{C}-\mathrm{O}-\mathrm{C}\end{array}$ & $\begin{array}{c}\mathrm{C} 3(287.3-287.4 \mathrm{eV}) \\
\mathrm{O}-\underline{\mathrm{C}}-\mathrm{N}- \\
-\mathrm{N}-\underline{\mathrm{C}}-\mathrm{N}-\end{array}$ & $\begin{array}{c}\mathrm{C} 4(288.8-289.1 \mathrm{eV}) \\
-\mathrm{N}-\underline{\mathrm{C}}=\mathrm{O} \\
\mathrm{O}-\underline{\mathrm{C}}=\mathrm{O}\end{array}$ \\
\hline $100 / 0(\mathrm{U})$ & 63.29 & 19.62 & 10.76 & 6.33 \\
\hline $90 / 10(\mathrm{~F})$ & 63.29 & 22.15 & 8.86 & 5.70 \\
\hline $80 / 20(\mathrm{I})$ & 70.46 & 14.49 & 9.42 & 5.62 \\
\hline $70 / 30(\mathrm{H})$ & 71.43 & 11.43 & 9.28 & 7.86 \\
\hline
\end{tabular}

In the present study the variation in the ratio of UF/EPU of composite adhesive was attained by changing the content of EPU. An increase in the ratio of UF/EPU resulted in an increase in the content of carbon to carbon single or carbon to hydrogen bonds $(\mathrm{C} 1-\mathrm{C}$ or $\mathrm{C} 1-\mathrm{H})$. On the other hand, it appears that the sum of the content of the contributions of carbon atoms involved in single bonds with oxygen increased 3\% first and subsequently decreased gradually by $6.19 \%$. This fact may be attributed to the large interchange benzene ring association and hence an increase in $\mathrm{C}=\mathrm{C} / \mathrm{C}-\mathrm{H}$ bond strength was more due to a higher UF/EPU ratio. In addition, the benzene ring can improve the cohesion of the straw layer with glue line. Then, the main contribution to $\mathrm{C} 3$ would essentially be due to the $-\mathrm{N}-\mathrm{C} 3-\mathrm{N}$ - bond (i.e. methylene bridges) instead of $-\mathrm{N}-\mathrm{C} 3-\mathrm{O}-$ (methylene ether bridge) contributions. But the percent content of $\mathrm{C} 3$ does not represent a major change. On the other hand, with increasing EPU content, the urethane $(-\mathrm{N}-\mathrm{C}=\mathrm{O})$ functional group increased, which led to increased cohesion and markedly improved strength of wheat straw particleboards. Thus, it can be concluded that the main impact of the ratio of UF/PEU is due not to physical but rather to chemical medications. 

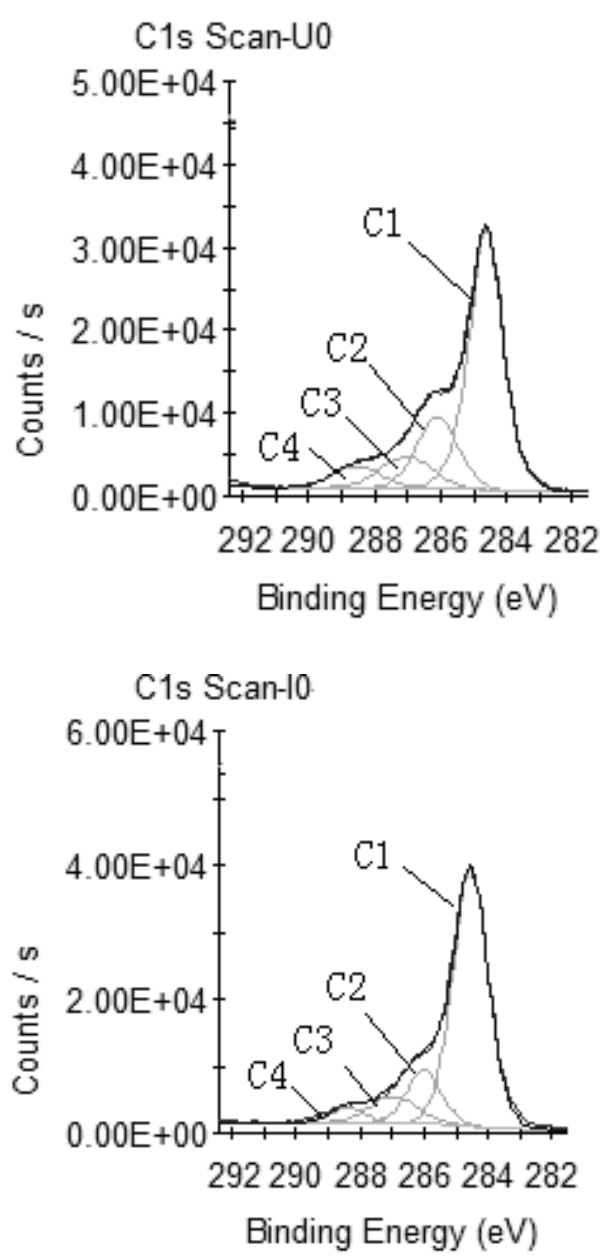
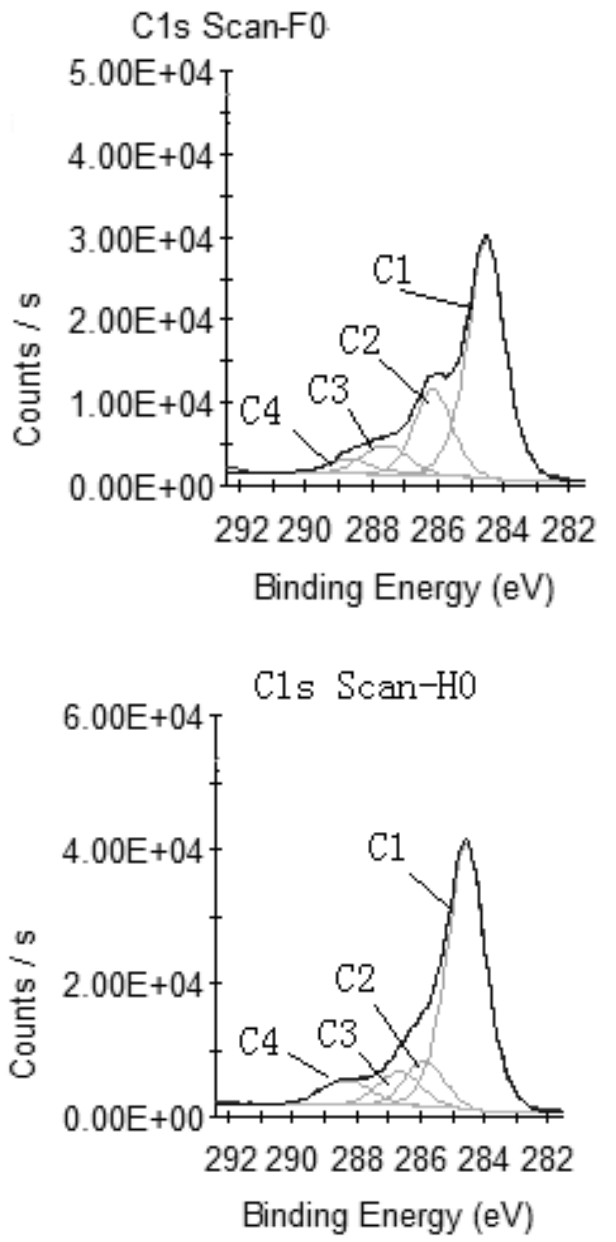

Fig. 3. Carbon 1s peak-fitting signal of the particleboards with (UF/EPU)

In fact, EPU can enhance the reaction conditions of the wheat surfaces by high reactivity to the wheat surface. Therefore, physical and chemical changes of wheat surfaces interfere with adhesion strength of the adhesive consequently. From the results of XPS analysis, it was clear that the urethane groups $(-\mathrm{NH}-\mathrm{C}=\mathrm{O})$ ) attached onto the surface of the wheat straw particleboards, and these groups were useful for improved the strength of polymers to make wheat straw particleboards. As a result, the composite adhesive of UF/EPU could contribute the excellent mechanical, thermal, and waterresistant properties to the wheat straw particleboards.

\section{Observation of Wheat Straw Particleboards by Scanning Electron Microscopy (SEM)}

SEM pictures of wheat straw particleboards with different proportions of UF/EPU are shown in Fig 4. 




Fig. 4. SEM micrographs of straw particleboards with different proportions of UF/EPU: (a) proportion of 100/0; (b) proportion of 9010; (c) proportion of 80/20; (d) proportion of 70/30

From the SEM pictures it is apparent that the morphology of wheat straw particleboards with urea formaldehyde resin was modified by EPU. Particleboards made from different ratios $(100 / 0,90 / 10,80 / 20$, and 70/30) of composite adhesive were investigated. The wheat straw particleboard specimens treated by sputter-coating with gold provided good analysis of scanning electron microscopy, as shown in Figs. 4(a) through 4(d). The wheat straw particleboard that was prepared with a 100/0 ratio of UF/EPU (unmodified UF) clearly shows the interfacial structure between wheat straw and urea formaldehyde resin. A large number of solidified particles of cured UF resin could be exfoliated and well dispersed into to the straw cell wall, but the distribution was non-uniform. There were relatively few glue spots of particleboard with UF resin. With a mixture ratio of $90 / 10$ the amount of glue after curing the adhesive layer was slightly less 
than in the case of the $100 / 0$ ratio, and the distribution was very good. Cross-sectional observations from the sample prepared with an 80/20 ratio showed only a few fissures and a more even distribution into the straw catheter holes and thin-walled elements, playing a role similar to that of nails. In addition, it can be seen in Fig. 5(d) with the ratio of 70/30 UF/EPU; there was a great deal of glue left in the fractured surfaces of boards. The reason for this behavior is that the content of the EPU adhesive increased, which led to a rapid increase of the viscosity of composite adhesive. Furthermore, the highly reactive EPU contains the $-\mathrm{NCO}$ functional group, which causes uneven distribution in the glue line of boards. As a result, the SEM results revealed that UF/EPU composites using 80/20 had good particle dispersion and particle-matrix adhesion.

\section{CONCLUSIONS}

1. In conclusion, the results of this study indicate that wheat straw is a suitable raw material for making particleboards with special composite adhesive. The results of differential scanning calerimetry measurements indicated that emulsifiable pMDI (EPU) could accelerate the cure rate of the UF resin effectively, achieving better thermo-stability of the boards. All the particleboards made in this study exceeded the minimum mechanical property requirement of national standards.

2. Regarding the binding ability and cost, better performance of wheat straw particleboard bonded with composite adhesive can be obtained at a UF/EPU ratio of $80 / 20$, a hot-press temperature of $170{ }^{\circ} \mathrm{C}$, a density of $0.75 \mathrm{~g} / \mathrm{cm}^{3}$, a hot press time of 6 min, and adhesive amounts of $10 \%$ based on the dry amounts of wheat straw.

3. From the results of DMA, XPS, and SEM analysis, it was clear that the urethane groups $(-\mathrm{NH}-\mathrm{C}=\mathrm{O}))$ were attached onto the surface of the wheat straw particleboards, and these groups were useful for improving the strength and thermal stability of wheat straw particleboards. Also, the composite adhesive of UF/EPU could contribute the excellent mechanical, thermal, and water-resistant properties to the wheat straw particleboards.

4. All in all, 80/20 of UF/EPU ratio particleboard prepared with the best overall performance. Thus the preparation and characterization of wheat straw particleboard, as described in this paper, provides a theoretical basis for the application of wheat straw.

\section{ACKNOWLEDGEMENTS}

The authors wish to acknowledge the financial support of National Nature Science Foundation of P R China (grant No.30871984) and the support of the project of Harbin (grant No. 2008AA4BG006). Special thanks to outstanding doctoral dissertation foster support for the study and supported by the Fundamental Research Funds for the Central Universities (DL10BB21). 


\section{REFERENCES CITED}

Blencowe, A., Clarke, A., Drew, M. G. B., and Hayes, W. (2006). "Alternative syntheses of linear polyurethanes using masked isocyanate monomers," Reactive and Functional Polymers 66, 1284-1295.

Boquillon, N., Elbez, G., and Schonfeld, U. (2004). "Properties of wheat straw particleboards bonded with different types of resin," The Japan Wood Research Society 50, 230-235.

Elbert, A. A. (1995). "Influence of hardener systems and wood on the formaldehyde emission from urea-formaldehyde resin and particleboard," Holzforschung 49(4), 358-362.

Gallbraith, C. J. (1986). "Recent developments in the full-time manufacture of allisocyanate bonded structural composite boards," In: Proc. of the 20th Particleboard Symp., WSU, 55-81.

Gu, J. Y., Wei, S. Y., and Zhu, L. B. (2004). "Study on curing agents systems of ureaformaldehyde resin," China Adhesives 13(2), 4-8.

Gu, J. Y., Zhu, L. B., and Ono, H. (2005). "Study on curing mechanism of lowformaldehyde-emission urea-formaldehyde resins," Chemistry and Industry of Forest Products 25(4), 11-16.

Guru, M., Tekeli, S., and Bilici, I. (2005). Manufacturing of urea-formaldehyde-based composite particleboard from almond shell," Materials and Design 27(10), 11481151.

Han, G., Zhang, C., Zhang, D., Umenura, D., and Kawai, S. (1998). "Upgrading of urea formaldehyde-bonded reed and wheat straw particleboards using silane coupling agents," Journal Wood Science 44, 282-286.

Jiang, X., Gu, J., Bai, X., Lin, L., and Zhang, Y. (2009). "The influence of acid treatment on multi-walled carbon nanotubes," Pigment and Resin Technology 38(3), 165-173.

Kang, E. C. (2001). "Studies on the compositions of isocyanate prepolymer and the adhesion properties of its wood based panel: Effects of the -NCO contents, additives and adhesion factors," Ph.D. thesis, Konkuk Univ., Seoul, Korea.

Kang, E. C., Park, S. B., Sun, X. Z. S., Park, B. D., and Park, H. (2007). “Curing behaviour of urea-formaldehyde resin modified with cooking waste oil-based pMDI prepolymer and its influence on particleboard properties," Forest Products Journal 57(6), 51-59.

Li, H., Zhou, J. Q., Zhu, R. T., and Ling, X. (2010). “The evolution of porosity in bulk nanocrystalline materials during plastic deformation and its effect on the mechanical behaviour," Material and Design 31(2), 1003-1006.

Liu, J. S., Liu, S. P. Wu, S. Q., and Huang, P. C. (2009). "Preparation of Epoxy Modified Polysiloxane Microemulsions," Iranian Polymer Journal 18(2), 159-166.

Liu, Z. M., Wang, F. H., and Sun, R. Z. S. (2002). "Analysis on structural features and surface elements of wheat straw," J. Northeast Forest Univ. 30, 62-65.

Mo, X. Cheng, E., Wang, D., and Sun, X. S. (2003). "Physical properties of mediumdensity wheat straw particleboard using different adhesive," Industrial Crops Products 18, 47-53. 
Mo, X., Hu, J. Sun, X. S., and Ratto, J. A. (2001). "Compression and tensile strength of low-density straw-protein particleboard," Industrial Crops and Products 14(1), 1-9.

Nguila, I. G., Petrissans, M., Lambert, J., Ehrhardt, J. J., and Gerardin, P. (2006). "XPS characterization of wood chemical composition after heat-treatment," Surface Interface Anal. 38, 1336-1342.

No, B. Y. and Kim, M. G. (2005). "Curing of low level melamine-modified ureaformaldehyde particleboard binder resins studied with dynamic mechanical analysis (DMA)," Journal of Applied Polymer Science, 97, 337-389.

Rezaei, F., Yunus, R., and Ibrahim, N. A. (2009). "Effect of fiber length on thermomechanical properties of short carbon fiber reinforced polypropylene composites," Materials and Design 30, 260-263.

Sellers, T. S. (2001). "Wood adhesive innovations and applications in North America," Forest Products Journal 51(6), 12-22.

Simon, C., George, B., and Pizzi, A. (2002). "UF/pMDI wood adhesives: Networks blend were copolymerization," Holzforschung 56, 327-334.

Singha, A. S., and Thakur, V. K. (2008). "Effect of fibre loading on properties of ureaformaldehyde matrix based green composites," Iranian Polymer Journal 17(11), 861873.

Wang, D., and Sun, X. S. (2002). "Low density particleboard from wheat straw and corn pith," Industrial Crops Products 15(1), 43-50.

Wang, Z. L., Wang, E. J., Zhang, S. X., Wang, Z., and Ren, Y. P. (2009). "Effects of cross-linking on mechanical and physical properties of agricultural residues/recycled thermoplastics composites," Industrial Crops and Products 29, 133-138.

Watts, J. F., Abel, M. L., Perruchot, C., Lowe, C., Maxted, J. T., and White, R. G., (2001). "Segregation and crosslinking in urea formaldehyde/epoxy resins: A study by high-resolution XPS," Journal of Electron Spectroscopy and Related Phenomena, 121, 233-247.

Xu, J. C., Yu, H., Xia, L., Li, X. L., and Yang, H. (2004). "Effects of some factors on the tribological properties of the short carbon fiber-reinforced copper composite," Materials and Design 25, 489-493.

Yao, J., Xu, X.W., and Feng, Y. Y. (2003). "FTIR studies on the chemical composition of wheat straw in different layers," Spectro. Spec. Anal. 23, 58-60.

Youngquist, J. A. (1999). "Wood-based composites and panel products," In: Wood Handbook: Wood as an Engineering Material. Gen. Tech. Rept. FPL-GRT113.USDA Forest Serv., Prod. Lab., Madison, WI : 1-31.

Zheng, Y. (2000). "Kinetic modelling of enzymatic saccharification and particleboard characteristics of saline biomass," PhD Thesis, University of California, 200-210.

Zheng, Y., Zhang, R. Z., Jenkins, B. M., and Blunk, S. (2007). "Particleboard quality characteristics of saline jose tall wheatgrass and chemical treatment effect," Bioresource Technology 98, 1304-1310.

Zhou, D., and Mei, C. (2000). "Development of agriculture straw material industry in the 21 st century," Journal Nanjing Forestry University, China, No. 24, 1-5.

Article submitted: September 6, 2010; Peer review completed: November 19, 2010;

Revised version received and accepted: December 18, 2010; Published: Dec. 23, 2010. 